Palavras chave:

Nutrição florestal

Ciclagem de nutrientes

Sustentabilidade nutricional

Histórico:

Recebido 10/02/2015

Aceito 15/1 1/2015

Keywords:

Forestry nutrition

Nutrient cycling

Nutritional sustainability

Correspondência: rwitschoreck@yahoo.com.br
Rudi Witschoreck', Mauro Valdir Schumacher'

\section{ALOCAÇÃO DE NUTRIENTES EM POVOAMENOS DE Eucalyptus saligna Sm. NA REGIÃO DE GUAÍBA - RIO GRANDE DO SUL}

RESUMO: Este trabalho, realizado em povoamentos de Eucalyptus saligna Sm., entre 2 e 7 anos de idade, na região de Guaíba - RS, teve como objetivo: estimar o estoque de nutrientes na biomassa. Com base no inventário florestal, árvores de diâmetro médio foram coletadas e fracionadas em folha, galho, casca do tronco, madeira do tronco e raiz. A serapilheira acumulada foi avaliada com unidades amostrais de $\mathrm{I}^{2}$. Amostras dos componentes arbóreos e de serapilheira foram coletadas para estimativa da massa seca e da concentração de nutrientes. $O$ estoque de nutrientes foi obtido pelo produto entre a biomassa média de cada componente e a concentração média de nutrientes. Para a média dos povoamentos, o estoque de nutrientes apresentou a seguinte ordem de acúmulo, para os componentes da biomassa: madeira do tronco $>$ raiz $>$ folha $>$ casca $>$ galho; e para nutrientes: $\mathrm{Ca}>\mathrm{N}>\mathrm{K}>\mathrm{Mg}>\mathrm{P}$.

\section{NUTRIENT ALLOCATION IN Eucalyptus saligna Sm. STANDS IN THE REGION OF GUAÍBA - RIO GRANDE DO SUL}

ABSTRACT: This research conducted in Eucalyptus saligna Sm. stands, between 2 and 7 years of age, in the region of Guaíba - RS, had as objective: to estimate the nutrients stock in the biomass. On the basis of the forest inventory, trees of medium diameter were collected and fractionated in leaf, branch, bark, wood and root. The accumulated litter was evaluated with sampling units of $\mathrm{I}^{2}$. Samples of arboreal components and litter were collected to estimate the dry matter and nutritional content. Nutrients stock was obtained through the product between the average biomass of each component and the average concentration of nutrients. For the average of stands, the stock of nutrients showed the following order of accumulation, for biomass components: wood $>$ root $>$ leaf $>$ bark > branch; and for nutrients: $\mathrm{Ca}>\mathrm{N}>\mathrm{K}>\mathrm{Mg}>\mathrm{P}$. 


\section{INTRODUÇÃO}

A expressão do potencial produtivo de uma espécie vegetal (fixado geneticamente) depende de fatores externos de natureza edáfica, climática e biológica, passíveis ou não de manejo.

Os ecossistemas florestais, naturais ou implantados, são abertos e sujeitos a entradas e saídas de radiação, $\mathrm{CO}_{2}$, água e nutrientes (fatores de produção), os quais determinam a produtividade vegetal (BINKLEY, 1986). Em povoamentos florestais, tanto a produção como a manutenção da capacidade produtiva depende da espécie(capacidade de obter e utilizar os recursos) associado ao manejo adequado dos fatores de produção (BINKLEY et al., 1997).

Juntamente com a água, os nutrientes são os fatores ambientais que mais limitam a produtividade primária (LAMBERSet al., 2008). A produtividade de todos os ecossistemas responde a adição de um ou mais nutrientes, o que indica uma ampla limitação nutricional (EPSTEIN e BLOOM, 2006; LAMBERS et al., 2008).

Diferentemente da radiação solar que tem uma entrada relativamente constante nos ecossistemas, partindo de uma fonte que pode ser convenientemente considerada inesgotável, os nutrientes são finitos e suas reservas dependem da ciclagem nos ecossistemas (KIMMINS, 1987).

Entre os fatores de produção, os aspectos ligados a nutrição certamente são os que apresentam - maior potencial de manejo, seja pela capacidade de limitar a produtividade, seja pela ampla gama de insumos industrializados e resíduos que podem ser utilizados na fertilização e correção do solo, além de as inúmeras práticas de manejo que visam a manutenção da capacidade produtiva dos sítios florestais.

$O$ entendimento da ciclagem de nutrientes nos ecossistemas florestais é um pré-requisito essencial para a compreensão e a predição dos efeitos da nutrição no crescimento da floresta (LANDSBERG, 1986); e um dos aspectos fundamentais para a manutenção da produtividade florestal (REIS e BARROS, 1990). As entradas de nutrientes no sistema podem ocorrer através das deposições atmosféricas (secas e úmidas), intemperismo geológico, fixação biológica de nitrogênio e fertilização, enquanto que as saídas incluem a volatilização pelas queimadas ou pela desnitrificação, lixiviação e erosão, assim como, a colheita da biomassa (PRITCHETT, 1990). Normalmente a colheita é a principal via de exportação de nutrientes dos sítios florestais, sobretudo se realizada em rotações curtas e envolvendo outros componentes da biomassa, além da madeira.
Para auxiliar no manejo nutricional, este trabalho teve como objetivo estimar o estoque de nutrientes nos diferentes componentes da biomassa ao longo do ciclo produtivo do Eucalyptus saligna.

\section{MATERIAL E MÉTODOS}

\section{Caracterização da área do estudo}

O estudo foi realizado em plantações de Eucalyptus saligna de propriedade da empresa CMPC Celulose Riograndense.

Segundo a classificação de Köppena região pertence ao tipo climático Cfa (subtropical), que se caracteriza por chuvas bem distribuídas durante $\circ$ ano, temperatura média das máximas superior a $22{ }^{\circ} \mathrm{C}$ e média das mínimas variando entre -3 e $18^{\circ} \mathrm{C}$.

Os povoamentos envolvidos no estudo estão localizados na Depressão Central do Rio Grande do Sul. Essa região corresponde à área da bacia sedimentar do Paraná não coberta pelo derrame de lavas do Planalto (basáltica e riolito) e limitada ao sul pelo Escudo Sul-rio-grandense, composto por rochas graníticas(VIEIRA, 1984). Essa condição permitiu a formação de uma grande diversidade de solos, como pode ser observado na Tabela I.

\section{Procedimento de campo}

Inicialmente, foi realizado um inventário florestal com o objetivo de caracterizar os povoamentos quanto ao diâmetro à altura do peito $(1,30 \mathrm{~m}$ de altura em relação ao solo) e a altura total das árvores. Em cada povoamento foram delimitadas 3 parcelas englobando 6 linhas de plantio, totalizando 60 árvores por parcela. Os diâmetros das árvores foram medidos com fita diamétrica e as alturas com hipsômetro Forestor Vertex ${ }^{\circledR}$.

A coleta de biomassa dos componentes acima do solo (folha, galho, casca e madeira do tronco) consistiu no abate de três árvores-amostra por povoamento: uma árvore de diâmetro médio; uma árvore de diâmetro médio mais um desvio-padrão e uma árvore de diâmetro médio menos um desvio-padrão; totalizando 132 árvores-amostra em 44 povoamentos entre 2 e 7 anos de idade (Tabela I). As árvores selecionadas com base nesse critério foram seccionadas ao nível do solo e a biomassa foi fracionada nos diferentes componentes.

A biomassa de raiz, em função da dificuldade de amostragem, foi avaliada em uma árvore de diâmetro médio por povoamento, totalizando 17 árvores-amostra (Tabela I). A biomassa de cada árvore-amostra foi 
Tabela I Caracterização dos povoamentos de Eucalyptus saligna estudados na região de Guaíba - RS.

Table I Caracterization of Eucalyptus saligna stands studied in the region of Guaíba-RS.

\begin{tabular}{|c|c|c|c|c|}
\hline Povoamentos amostrados & Idade (anos) & Espaçamento (m) & Município & Tipo de solo \\
\hline \multicolumn{5}{|c|}{ Coleta de biomassa acima do solo } \\
\hline 3 & 2 & $3 \times 2$ & Barra do Ribeiro & Neossolo Quartzarênico \\
\hline 3 & 2 & $3 \times 2$ & Barra do Ribeiro & Planossolo Hidromórfico \\
\hline I & 2 & $3 \times 2$ & Barra do Ribeiro & Argissolo Vermelho-amarelo \\
\hline 3 & 3 & $3 \times 2$ & Barra do Ribeiro & Neossolo Quartzarênico \\
\hline 3 & 3 & $3 \times 2$ & Mariana Pimentel & Argissolo Vermelho Distrófico \\
\hline 3 & 3 & $3 \times 2$ & São Jerônimo & Planossolo Hidromórfico \\
\hline 1 & 3 & $3 \times 2$ & Barra do Ribeiro & Neossolo Quartzarênico \\
\hline I & 3 & $3 \times 2$ & Barra do Ribeiro & Planossolo Hidromórfico \\
\hline I & 4 & $3 \times 2$ & Barra do Ribeiro & Argissolo Vermelho-amarelo \\
\hline 1 & 4 & $3 \times 2$ & Barra do Ribeiro & Neossolo Quartzarênico \\
\hline 3 & 4 & $3 \times 2$ & Barra do Ribeiro & Planossolo Háplico \\
\hline 3 & 4 & $3 \times 2$ & Eldorado do Sul & Neossolo Regolítico \\
\hline I & 6 & $3 \times 3$ & Barra do Ribeiro & Neossolo Quartzarênico \\
\hline I & 5 & $3 \times 3$ & Barra do Ribeiro & Planossolo Hidromórfico \\
\hline 1 & 4 & $3 \times 2$ & Mariana Pimentel & Argissolo Vermelho \\
\hline 1 & 4 & $3 \times 2$ & São Jerônimo & Planossolo Hidromórfico \\
\hline I & 5 & $3 \times 3$ & Barra do Ribeiro & Planossolo Háplico \\
\hline 1 & 5 & $3 \times 3$ & Barra do Ribeiro & Neossolo Quartzarênico \\
\hline $\mathrm{I}$ & 5 & $3 \times 3$ & Eldorado do Sul & Neossolo Regolítico \\
\hline 1 & 6 & $3 \times 3$ & Mariana Pimentel & Argissolo Vermelho \\
\hline I & 6 & $3 \times 3$ & São Jerônimo & Planossolo Hidromórfico \\
\hline 3 & 6 & $3 \times 3$ & Tapes & Argissolo Vermelho-amarelo \\
\hline I & 7 & $3 \times 3$ & Barra do Ribeiro & Planossolo Háplico \\
\hline 1 & 7 & $3 \times 3$ & Tapes & Argissolo Vermelho-amarelo \\
\hline I & 7 & $3 \times 3$ & Eldorado do Sul & Neossolo Regolítico \\
\hline 3 & 7 & $3 \times 3$ & Guaíba & Argissolo Vermelho \\
\hline \multicolumn{5}{|c|}{ Coleta de biomassa de raiz } \\
\hline 2 & 2 & $3 \times 2$ & Eldorado do Sul & Argissolo Vermelho-amarelo \\
\hline I & 3 & $3 \times 2$ & Eldorado do Sul & Argissolo Vermelho-amarelo \\
\hline 2 & 3 & $3 \times 2$ & Eldorado do sul & Argissolo Vermelho \\
\hline 3 & 4 & $3 \times 2$ & Guaíba & Cambissolo Háplico \\
\hline 1 & 5 & $3 \times 2$ & Arroio dos Ratos & Cambissolo Háplico \\
\hline 1 & 5 & $3 \times 3$ & Arroio dos Ratos & Argissolo Vermelho-amarelo \\
\hline I & 5 & $3 \times 3$ & Eldorado do Sul & Argissolo Vermelho-amarelo \\
\hline 2 & 6 & $3 \times 3$ & Guaíba & Neossolo Litólico \\
\hline 1 & 6 & $3 \times 2$ & Eldorado do Sul & Argissolo Vermelho-amarelo \\
\hline 1 & 7 & $3 \times 2$ & Eldorado do Sul & Argissolo Vermelho-amarelo \\
\hline 2 & 7 & $3 \times 2$ & Guaíba & Argissolo Vermelho-amarelo \\
\hline
\end{tabular}


obtida mediante escavação manual de um bloco de solo estabelecido pela área útil de cada árvore-amostra (definida pelo espaçamento entre árvores) e profundidade de um metro. A separação do solo das raízes foi realizado com o uso de peneira com malha de $7 \mathrm{~mm}$.

A biomassa de cada componente foi pesada e amostrada. As amostras coletadas foram pesadas em balança de precisão, identificadas e acondicionadas em sacos de papel.

A serapilheira foi coletada com $\circ$ uso de um gabarito de I $\mathrm{m} \times \mathrm{I} \mathrm{m}$. Foram coletadas cinco amostras distribuídas aleatoriamente no interior de cada povoamento, em dois povoamentos por idade, evitandose condições de bordadura ou qualquer outra situação atípica (não representativa).

\section{Análise química da biomassa}

As amostras de biomassa foram secas a 70 ${ }^{\circ} \mathrm{C}$ em estufa de circulação e renovação de ar, até a estabilização da massa, e pesadas em balança de precisão para determinação da massa seca. Após a secagem, as amostras foram moídas em moinho de lâminas do tipo Wiley com peneira de 20 mesh. As determinações analíticas dos macronutrientes: N, P, K, Ca e Mg foram realizadas segundo Tedesco et al. (1995).

\section{Análise estatística e determinação do estoque de nutrientes}

Com base no inventário florestal, foi determinada a média e o desvio-padrão para o diâmetro à altura do peito das árvores para definir as três classes de árvores-amostra em cada povoamento: árvore média; árvore média mais um desvio-padrão e árvore média menos um desvio-padrão.

A biomassa seca foi obtida baseado no teor de umidade das amostras, e o conteúdo de nutrientes, pelo produto entre a biomassa seca e o teor de nutrientes, em cada componente das árvores-amostra. $\mathrm{O}$ estoque de nutrientes por unidade de área foi estimado pelo produto entre o conteúdo médio de nutrientes em cada componente da biomassa das árvores-amostra e o número de árvores por hectare.

\section{RESULTADOS E DISCUSSÃO}

Na Tabelas 2 e Figuras I, são apresentados os estoques de nutrientes nos componentes da biomassa de Eucalyptus saligna nos povoamentos de diferentes idades, em valores absolutos e relativos, para macro e micronutrientes, respectivamente.

Considerando-se os valores médios, os principais componentes da biomassa arbórea em acúmulo de nutrientes foram: madeira do tronco > raiz $>$ folha $>$ casca $>$ galho; enquanto os nutrientes, apresentaram a seguinte ordem $\mathrm{Ca}>\mathrm{N}>\mathrm{K}>\mathrm{Mg}>\mathrm{P}$.

A distribuição de nutrientes geralmente difere do padrão observado para a biomassa, o que decorre da grande diferença na concentração de nutrientes entre os componentes (REIS e BARROS, 1990). O principal exemplo disso são as folhas, consideradas o centro metabólico da planta, é o componente com a maior concentração para a maioria dos nutrientes (MARSCHNER, 1995), e geralmente, apresentam - menor acúmulo de biomassa, principalmente em povoamentos adultos. A despeito da pequena biomassa relativa (apenas $2 \%$ ), tendo como base os povoamentos com 7 anos (possível idade de colheita), o componente folha representou I $5 \%$ do N, $9 \%$ do P, $8 \%$ do K, $7 \%$ do $\mathrm{Mg}, 5 \%$ do $\mathrm{Ca}$, do estoque total nos componentes arbóreos. Por outro lado, na mesma idade, a madeira do tronco, com $74 \%$ da biomassa total, acumulou $56 \%$ do P, $53 \%$ do K, $48 \%$ do N, 34 \% do Mg e $24 \%$ do Ca.

Os nutrientes presentes em menores quantidades relativas na folha e na madeira do tronco foram os mais abundantes na casca do tronco, o que é amplamente relatado na literatura científica para o eucalipto (PEREIRA et al., 1984a; PEREIRA et al., 1984b; SANTANA et al., 1999; SANTANA et al., 2008). A casca, apesar de ter representado somente $6 \%$ da biomassa média nos povoamentos com 7 anos de idade, acumulou $36 \%$ do Ca, $32 \%$ do $\mathrm{Mg}, 14 \%$ do $\mathrm{K}, \mathrm{I} 3 \%$ do P e $10 \%$ do N.

O componente galho apresentou acúmulo de nutriente mais proporcional à sua biomassa relativa de 4 \%, ou seja: $10 \%$ do $\mathrm{K}, \mathrm{Ca}$ e $\mathrm{Mg}, 7$ \% do $\mathrm{Ne} 6 \%$ do P, considerando-se os povoamentos de 7 anos de idade.

Devido, principalmente, à inerente dificuldade de amostragem da biomassa abaixo do solo, alguns estudos não consideram esse componente, no entanto, ficou evidente a importância das raízes, sobretudo para o estoque de nutrientes (Tabelas I e Figuras I). Com biomassa relativa média de $14 \%$ nos plantios de Eucalyptus saligna de 7 anos de idade, o sistema radicular representou $25 \%$ do Ca, 21 $\%$ do N, $16 \%$ do P e Mg e $15 \%$ do K.

Reis e Barros (1990) salientaram a importância de se considerar o sistema radicular nos estudos que avaliam a demanda de nutrientes por espécies florestais, bem como, quando o objetivo for analisar diferentes métodos de manejo sobre a produtividade de futuras rotações, especialmente no caso de espécies que se regeneram por brotação. 
Tabela 2 Estoque de nutrientes $\left(\mathrm{kg} \cdot \mathrm{ha}^{-1}\right)$ nos componentes arbóreos e na serapilheira acumulada, em povoamentos de Eucalyptussaligna, na região de Guaíba - RS.

Table 2 Nutrients stock $\left(\mathrm{kg} \cdot \mathrm{ha}^{-1}\right)$ in trees components and litter, in Eucalyptus saligna stands in the region of Guaíba-RS.

\begin{tabular}{|c|c|c|c|c|c|c|c|}
\hline \multirow{2}{*}{ Componentes da biomassa } & \multicolumn{6}{|c|}{ Idade pós-plantio (anos) } & \multirow{2}{*}{ Média } \\
\hline & 2 & 3 & 4 & 5 & 6 & 7 & \\
\hline \multicolumn{8}{|c|}{ Nitrogênio $(\mathrm{N})$} \\
\hline Copa & 123,44 & 174,93 & 168,82 & 157,33 & 132,22 & 111,40 & 144,86 \\
\hline Folha & 102,72 & 143,32 & 131,15 & 124,19 & 101,30 & 76,86 & 113,26 \\
\hline Galho & 20,72 & 31,61 & 38,67 & 33,14 & 30,92 & 34,54 & 31,60 \\
\hline Tronco & 50,29 & 124,52 & 167,65 & 209,42 & 318,75 & 307,17 & 196,30 \\
\hline Casca & 14,00 & 27,95 & 31,07 & 38,90 & 53,08 & 54,54 & 36,59 \\
\hline Madeira & 36,29 & 96,57 & 136,58 & 170,52 & 265,67 & 252,63 & $|59,7|$ \\
\hline Raízes & 38,32 & 71,07 & 90,96 & 127,33 & 130,55 & || $0,3 \mid$ & 94,76 \\
\hline Acima do solo & 173,73 & 299,45 & 337,47 & 366,75 & 450,97 & 418,57 & $34 I, 16$ \\
\hline Total arbóreo & 212,05 & 370,52 & 428,43 & 494,08 & 581,52 & 528,88 & 435,91 \\
\hline Serapilheira & 88,32 & 88,35 & 85,85 & 120,88 & 113,78 & 139,10 & 106,16 \\
\hline Estoque total & 300,37 & 458,87 & 514,28 & 614,96 & 695,30 & 668,66 & 542,07 \\
\hline \multicolumn{8}{|c|}{ Fósforo $(\mathrm{P})$} \\
\hline Copa & 14,16 & $|6,6|$ & $15,9 \mid$ & 17,74 & 10,89 & 8,49 & 13,97 \\
\hline Folha & 9,20 & 11,38 & 10,69 & 11,57 & 6,77 & 5,04 & 9,11 \\
\hline Galho & 4,96 & 5,23 & 5,22 & 6,17 & 4,12 & 3,45 & 4,86 \\
\hline Tronco & 8,26 & 18,66 & 23,66 & 29,86 & 34,45 & 39,57 & 25,74 \\
\hline Casca & 2,01 & 3,55 & 4,35 & 6,72 & 7,08 & 7,41 & 5,19 \\
\hline Madeira & 6,25 & 15,11 & $|9,3|$ & 23,14 & 27,37 & 32,16 & 20,56 \\
\hline Raízes & 2,87 & 5,16 & 6,38 & 10,06 & 10,50 & 8,98 & 7,33 \\
\hline Acima do solo & 22,42 & 35,27 & 39,57 & 47,60 & 45,34 & 48,06 & 39,71 \\
\hline Total arbóreo & 25,29 & 40,43 & 45,95 & 57,66 & 55,84 & 57,04 & 47,04 \\
\hline Serapilheira & 4,92 & 5,10 & 5,83 & 7,35 & 5,53 & 7,14 & 5,98 \\
\hline Estoque total & 30,21 & 45,53 & 51,78 & 65,01 & 61,37 & 64,18 & 53,01 \\
\hline \multicolumn{8}{|c|}{ Potássio (K) } \\
\hline Copa & 67,57 & 90,42 & 85,53 & 66,43 & 62,52 & 68,82 & 73,55 \\
\hline Folha & 44,73 & 57,59 & 50,23 & 35,75 & 32,85 & 30,85 & 42,00 \\
\hline Galho & 22,84 & 32,83 & 35,30 & 30,68 & 29,67 & 37,97 & 31,55 \\
\hline Tronco & 60,06 & 147,60 & I79, II & 175,98 & 244,40 & $274,4 I$ & 180,26 \\
\hline Casca & 13,83 & 30,89 & 34,64 & 36,72 & 49,77 & 55,04 & 36,82 \\
\hline Madeira & 46,23 & $|16,7|$ & 144,47 & 139,26 & 194,63 & 209,86 & $|4|, 86$ \\
\hline Raízes & 38,32 & 68,44 & 71,21 & 80,54 & 80,90 & 60,46 & 66,65 \\
\hline Acima do solo & 127,63 & 238,02 & 264,64 & $242,4 I$ & 306,92 & 343,23 & 253,81 \\
\hline Total arbóreo & 165,95 & 306,46 & 335,85 & 322,95 & 387,82 & 403,69 & 320,45 \\
\hline Serapilheira & 16,62 & 22,18 & 19,74 & 23,62 & 20,17 & 22,69 & 20,84 \\
\hline Estoque total & 182,57 & 328,64 & 355,59 & 346,57 & 407,99 & 416,87 & 339,71 \\
\hline \multicolumn{8}{|c|}{ Cálcio (Ca) } \\
\hline Copa & 160,62 & 180,55 & 165,28 & 122,06 & 93,95 & 96,87 & 136,56 \\
\hline Folha & 68,03 & 73,26 & 59,08 & 47,80 & 30,05 & 30,80 & 51,50 \\
\hline Galho & 92,59 & 107,29 & 106,20 & 74,26 & 63,90 & 66,07 & 85,05 \\
\hline
\end{tabular}




\begin{tabular}{|c|c|c|c|c|c|c|c|}
\hline \multirow{2}{*}{ Componentes da biomassa } & \multicolumn{6}{|c|}{ Idade pós-plantio (anos) } & \multirow{2}{*}{ Média } \\
\hline & 2 & 3 & 4 & 5 & 6 & 7 & \\
\hline \multicolumn{8}{|c|}{ Cálcio (Ca) } \\
\hline Tronco & 84,74 & 213,70 & $28 I, 31$ & 267,74 & 364,80 & 404,31 & 269,43 \\
\hline Casca & 58,94 & $|50,9|$ & 192,95 & 195,78 & 195,29 & 241,03 & 172,48 \\
\hline Madeira & 25,80 & 62,79 & 88,36 & 71,96 & $|69,5|$ & 163,28 & 96,95 \\
\hline Raízes & 86,21 & 177,96 & 182,17 & 202,27 & 221,24 & 170,87 & 173,45 \\
\hline Acima do solo & 245,36 & 394,25 & 446,59 & 389,80 & 458,75 & 501,18 & 405,99 \\
\hline Total arbóreo & 331,57 & 572,21 & 628,76 & 592,07 & 679,99 & 672,05 & 579,44 \\
\hline Serapilheira & 107,97 & 177,52 & 193,44 & 238,22 & 142,83 & 242,99 & 183,83 \\
\hline Estoque total & 439,54 & 749,73 & 822,20 & 830,29 & 822,82 & 915,04 & 763,27 \\
\hline \multicolumn{8}{|c|}{ Magnésio (Mg) } \\
\hline Copa & 29,52 & 39,44 & 44,36 & 29,62 & 28,52 & 29,12 & 33,43 \\
\hline Folha & 17,07 & 21,70 & 21,57 & 14,97 & 13,49 & 12,10 & 16,82 \\
\hline Galho & 12,45 & 17,74 & 22,79 & 14,65 & 15,03 & 17,02 & $|6,6|$ \\
\hline Tronco & 21,95 & 45,90 & 69,37 & 66,12 & 97,41 & 111,36 & 68,69 \\
\hline Casca & 12,63 & 21,64 & 31,68 & 34,58 & 51,37 & 53,66 & 34,26 \\
\hline Madeira & 9,32 & 24,26 & 37,69 & 31,54 & 46,04 & 57,70 & 34,43 \\
\hline Raízes & 14,37 & 25,71 & 26,92 & 34,28 & 45,57 & 27,17 & 29,00 \\
\hline Acima do solo & 51,47 & 85,34 & 113,73 & 95,74 & 125,93 & 140,48 & 102,12 \\
\hline Total arbóreo & 65,84 & 111,05 & 140,65 & 130,02 & 171,50 & 167,65 & 131,12 \\
\hline Serapilheira & 15,19 & 22,95 & 27,32 & 33,43 & 23,63 & 35,16 & 26,28 \\
\hline Estoque total & 81,03 & 134,00 & 167,97 & 163,45 & 195,136 & 202,81 & 157,40 \\
\hline
\end{tabular}

O estoque de nutrientes nos povoamentos florestais tende a apresentar um comportamento assintótico ao longo do ciclo produtivo, alcançando um estado de equilíbrio, onde os incrementos na biomassa são contrabalançados com a morte de indivíduos, deposição de serapilheira e ciclagem interna de nutrientes (WARING e SCHLESINGER, 1985), como pôde ser observado para alguns componentes da biomassa.

Em valores relativos, folha e galho, e consequentemente a copa, apresentaram tendência decrescente em função da idade dos povoamentos, ao passo que casca e madeira do tronco demonstraram tendência crescente. Devido a maior variabilidade ou a menor intensidade amostral, não foi possível estabelecer uma tendência para o estoque de todos os nutrientes para o componente raiz (Figura I).

De modo geral, prevaleceu a tendência crescente para $\circ$ estoque de nutriente na serapilheira acumuladaem função da idade dos povoamentos de Eucalyptus saligna. A remoção ou queima desse compartimento tem implicações importantes para o balanço de nutrientes. Se considerarmos os valores médios para os povoamentos com 7 anos de idade, a serapilheira acumulada representou $149 \%$ do Ca, $61 \%$ do $\mathrm{Mg}, 55 \%$ do N, $22 \%$ do P e II \% do K, estocados na madeiro do tronco.

Verifica-se que os estoques na serapilheira são mais expressivos para nutrientes com baixa mobilidade no tecido vegetal. Os nutrientes com alta mobilidade no floema são retranslocados para partes da planta com maior atividade metabólica o que reduz suas concentrações nos tecidos senescentes e aumenta a concentração dos demais (REIS e BARROS, 1990; PALLARDY, 2008). De acordo com Poggiani e Schumacher (2004), a ciclagem interna é um importante processo para a manutenção dos nutrientes no interior da planta, e é mais importante para nutrientes como $\mathrm{N}, \mathrm{P}, \mathrm{K}$ e $\mathrm{Mg}$, e menos importante para $\mathrm{Ca}, \mathrm{S}$ e micronutrientes. 

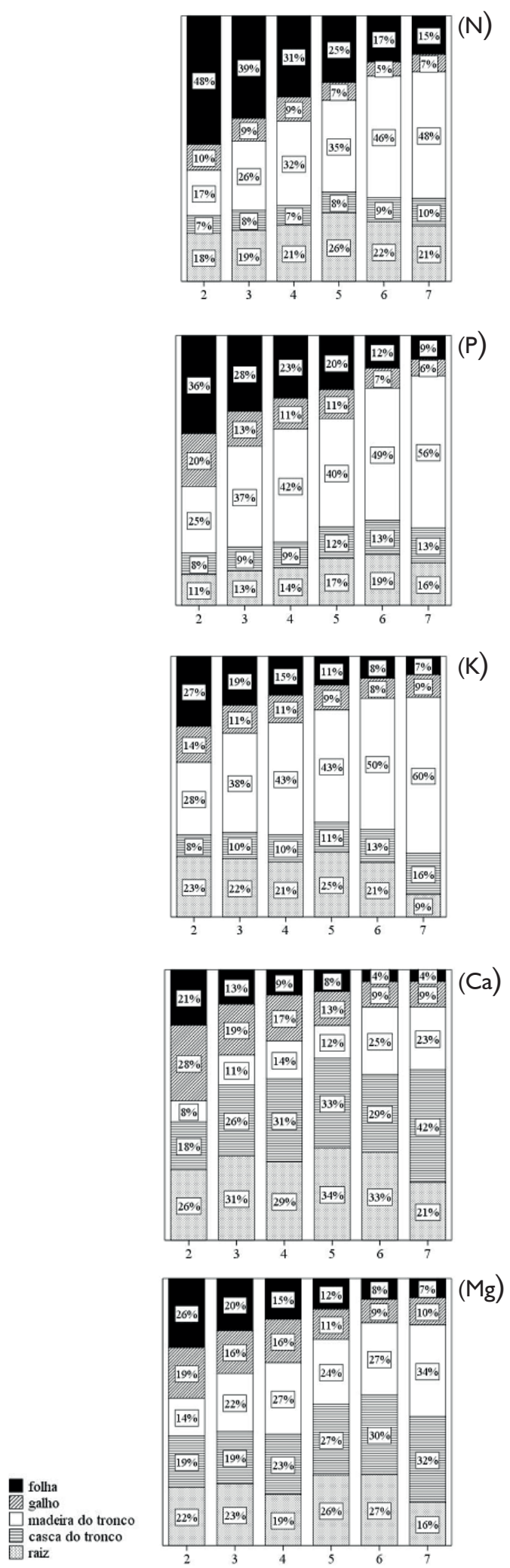

Figura I Distribuição relativa de nutrientes nos povoamentos de Eucalyptus saligna entre 2 e 7 anos de idade, na região de Guaíba - RS.

Figure I Relative distribution of nutrients in Eucalyptus saligna stands, between 2 and 7 years of age, in the region of Guaíba - RS.
A manutenção dos fluxos de nutrientes nos ecossistemas florestais é indispensável para a sustentabilidade nutricional. $O$ conhecimento da distribuição dos nutrientes nos diferentes componentes da biomassa florestal, ao longo do ciclo produtivo, é um importante subsídio para a tomada de decisões com o objetivo de manter a capacidade produtiva dos sítios florestais (REIS e BARROS, 1990; SANTANA et al., 1999; SANTANA et al., 2002; SCHUMACHER et al., 20I I).

Uma das medidas mais simples dentro dos princípios da sustentabilidade nutricional consiste na reposição dos nutrientes que são exportados por meio da remoção da biomassa na colheita (adubação de restituição ou reposição). Dentro dessa abordagem, considerando-se a colheita do tronco aos 7 anos de idade, as taxas de exportação de nutrientes (com base na biomassa arbórea total) ficaram acima de $50 \%$, ou seja: $69 \%$ para o P, $67 \%$ para o K, $66 \%$ para o Mg, $60 \%$ para o Ca e $58 \%$ para o N (Figura 2).

Colheita do Tronco $\square$ Colheita da Madeira $\square$ Descasque

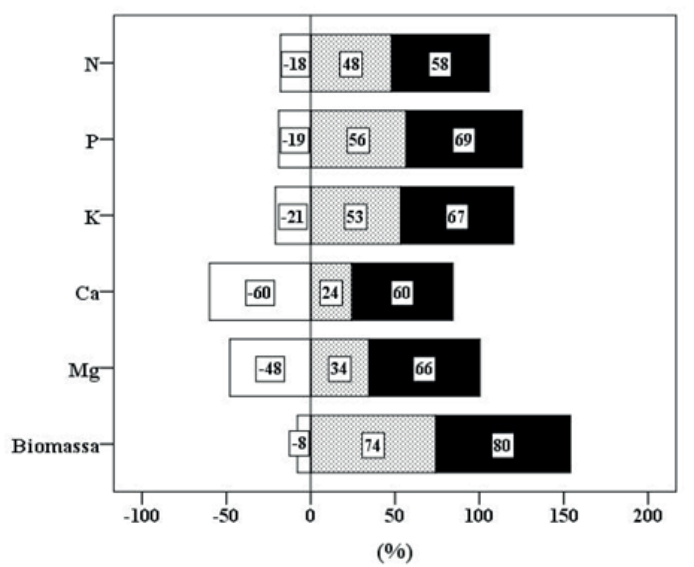

Figura 2 Taxas de exportação de nutrientes em função do método de colheita da biomassa nos povoamentos de Eucalycptus saligna aos 7 anos de idade, na região de Guaíba - RS.

Figure 2 Rate of nutrients exportation according to biomass harvesting method in Eucalyptus saligna stands, at 7 years old, in the region of Guaíba - RS.

Principalmente quando analisado em longo prazo, um simples ajuste na intensidade de colheita da biomassa pode representar a diferença entre um manejo nutricional sustentável e um deletério às reservas de nutrientes do sistema. Tomando-se os valores médios dos povoamentos com 7 anos de idade, o descasque no campo pode representar uma redução nas taxas de exportação de nutrientes de $60 \%$ para Ca, 48 \% para Mg, 21 \% para K, $19 \%$ para P e $18 \%$ para $\mathrm{N}$, mesmo que a casca tenha representado apenas $8 \%$ da biomassa do tronco. 


\section{REFERÊNCIAS BIBLIOGRÁFICAS}

BINKLEY, D. Forest nutrition management. John Wiley\& Sons, 1986. 290 p.

BINKLEY, D. et al. Stand development and productivity. In: NAMBIAR, E. K. S.; BROWN, A. G. (Ed.). Management of soil, nutrients and water in tropical plantation forests. Canberra: ACIAR Australia, CSIRO Australia, CIFOR Indonesia, 1997. p. 339-378.

EPSTEIN, E.; BLOOM, A. J. Nutrição mineral de plantas: princípios e perspectivas. $2^{\circ}$ ed. Tradução: Maria Edna Tenório Nunes. Londrina - PR: Editora Planta, 2006. 403 p.

KIMMINS, J. P. Forest Ecology. New York: Macmillan Publishing Company, 1987.53I p.

LAMBERS, H.; CHAPIN III, F. S.; PONTS, T. L. Plant physiological ecology. $2^{\text {nd }}$ Ed. New York: Springer, 2008. 604 p.

LANDSBERG, J. J. Physiological ecology of forest production. London: Academic Press, 1986. 198p.

MARSCHNER, $\mathrm{H}$. Mineral nutrition of higher plants. $2^{\text {nd }} \mathrm{Ed}$. London, Academic Press, 1995.889 p.

PALLARDY, S. Physiology of woody plants. $3^{\text {rd }}$ Ed. San Diego: Academic Press, 2008. 454 p.

PEREIRA, A. R. et al. Concentração e distribuição de nutrientes em Eucalyptusgrandis em função da idade, cultivado na região do cerrado. Brasil Florestal, Brasília, n. 59, p. 2737, jul./set. 1984a.

PEREIRA, A. R. et al. Produção de biomassa e remoção de nutrientes em povoamentos de Eucalyptuscitriodora e Eucalyptussaligna cultivados na região de cerrado de Minas Gerais. RevistaFloresta, Curitiba , v. 15, n. I/2, p. 8-16, jan./dez. 1984b.
POGGIANI, F; SCHUMACHER, M.V. Nutrient cycling in native forests. In: GONÇALVES, J.L. M.; BENEDETTI, V. (Ed.). Forest nutrition and fertilization.Translation: Ken McNabb.Piracicaba: IPEF, 2004, p.287-305.

PRITCHETT, W. L. Suelos forestales: propriedade, conservación y mejoramento. México: Limusa Noriega, 1990. $634 \mathrm{p}$.

REIS, M. G. F; BARROS, N. F. Ciclagem de nutrientes em plantios de eucalipto. In: BARROS, N. F.; NOVAIS, R. F. (Ed.). Relação solo eucalipto. Viçosa: Ed. Folha de Viçosa, 1990. p. 265-302.

SANTANA, R. C. et al. Biomassa e conteúdo de nutrientes de procedências de Eucalyptusgrandis e Eucalyptussaligna em alguns sítios florestais do Estado de São Paulo. ScientiaForestalis, Piracicaba - SP, n. 56, p. 155-169, dez. 1999.

SANTANA, R. C. et al. Eficiência de utilização de nutrientes e sustentabilidade da produção em procedências de Eucalyptusgrandis e Eucalyptussaligna em sítios florestais do estado de São Paulo. Revista Árvore, Viçosa - MG, v. 26, n. 4, p. 447-457, out./dez. 2002

SANTANA, R. C. et al. Estimativa de biomassa de plantios de eucalipto no Brasil. Revista Árvore, Viçosa - MG, v. 32, n. 4, p. 697-706, out./dez. 2008.

SCHUMACHER, M. V. et al. Biomassa em povoamentos de Eucalyptus spp. de pequenas propriedades rurais em Vera Cruz - RS.Ciência Florestal, Santa Maria - RS, v. 2I, n. I, p. I7-22, jan./mar., 201 I.

TEDESCO, M. J.; GIANELLO, C.; BISSANI, C. A.; BOHNEN, H.; VOLKWEISS, S. J. Análise de solo, plantas e outros materiais. 2.ed. Porto Alegre: Departamento de Solos, UFRGS, 1995. 174p. (Boletim Técnico, 5).

VIEIRA, E. F. Rio Grande de Sul: geografia física e vegetação. Porto Alegre: Sagra, 1984. 184 p.

WARING, R. H.; SCHLESINGER, W. H. Forest ecosystems: concepts and management. San Diego: Academic Press, 1985 